\title{
A numerical method of analyzing the composition of colored wastewater from dyeing plant
}

\author{
M. Jędrzejczak ${ }^{1}$ (i) $\cdot$ K. Wojciechowski ${ }^{1}$
}

Received: 3 August 2020 / Revised: 31 January 2021 / Accepted: 13 February 2021 / Published online: 26 March 2021

(c) The Author(s) 2021

\begin{abstract}
Studies on the effectiveness of removing colored impurities from wastewater after dyeing process obtained from five dyeing plants located in the Lodz region in Poland were performed as well as a comparative spectrophotometric analysis of wastewater before and after treatment, in the visible range of absorption of 350-750 nm, attributed to dyes from different groups and with different structures of chromophoric systems. It was found that the method of calculating differences in the total areas under the curves of absorption from the range of $280-800 \mathrm{~nm}$ cannot determine precisely the effectiveness of color wastewater treatment. The method using a normalization procedure of the relevant spectra and the analysis of their partial differences proposed in this work allows to describe the efficiency of the process more precisely and indicates the class of synthetic dyes used in dyeing processes, giving the opportunity to the selection of appropriate procedures for their removal or disposal. By analysis of II-derivative of absorption bands, amount of colored components in the wastewater and the effects of physicochemical and biological treatment have been identified. This made it possible to determine the class of the colored impurities remaining in the wastewater.
\end{abstract}

Keywords Colored wastewater treatment $\cdot$ Differential analysis $\cdot$ Normalization of spectra $\cdot$ Spectrophotometric analysis

\section{Introduction}

Dyes are a large group of compounds used in many industries. They are synthetic organic and organometallic compounds, having in their structure aromatic rings and the azo, nitroso, chinoid, polyene, etc. groups, which causes their breakdown and removal from wastewater and the environment to be very difficult. Removal of dyes from wastewater involves the use of numerous, often combined methods like biodegradation, coagulation, adsorption, oxidation and filtration. Due to imperfection of dyeing processes and side reactions (e.g., hydrolysis), from 2 to $50 \%$ of the dye may

Editorial responsibility: Tanmoy Karak.

Krzysztof Wojciechowski retired from Lodz University of Technology.

M. Jędrzejczak

malgorzata.jedrzejczak@p.lodz.pl

1 Institute of Environmental Engineering and Building Installations, Lodz University of Technology, Al.

Politechniki 6, 90-924 Lodz, Poland be lost in the dyeing processes and released to wastewater (Houk et al. 1991; Maćkowska et al. 2000).

Dyes mainly used in the textile industry are derived from diverse application groups (technical classification): acid metal complex, cationic, direct, reactive, disperse, vat and pigments. Soluble dyes used in the bath methods are generally derived from acetoacetic acid arylide, 1-phenyl3-metylopirazolon-5, naphthols, arylmethane and anthraquinone (Colour Index International 1999). Dyeing processes are multistage, periodic, continuous and semi-continuous. Beyond dyes, a number of adjuvants (detergents, leveling agents), and inorganic compounds and acids are used in dyeing processes.

Effluents from plants using natural and synthetic dyes in the technological processes are a significant problem. In particular, synthetic colors have a strong negative impact on the environment, due to their "visibility" and the potential harmfulness. Dyes contaminating the water impede processes of assimilation of carbon dioxide by acting as a color filter for the light essential for photosynthesis. Moreover, as a result of decomposition, they can form potentially carcinogenic and mutagenic compounds. Precise identification of these compounds is often impossible, because they are usually 
difficult to obtain by chemical synthesis. Therefore, it is also difficult to test their toxicity.

Colored wastewater treatment processes mainly focus on "discoloration," which is not always synonymous with purification. Effective color wastewater treatment methods have been developed for years allowing for a substantial reduction of pollution both by biological and physicochemical methods (McKay 1963; Banet et al. 1996; Chang and Kuo 2000; Kumar et al. 2006; Arora et al. 2007; Dafale et al. 2008; Kalaf 2008; Onat et al. 2010). Their disadvantage is the selectivity, i.e., efficacy relative to the specific types of dyes. In the case of other dyes, they are not very effective (Hou and Zhang 2011; BeltranHeredia and Martin 2008; Li and Guthrie 2010). Therefore, treatment methods of colored wastewater should be individualized and appropriate to the type or the chemical structure of the dye.

A popular method of controlling the purity of colored wastewater is a spectrophotometric analysis in the extended UV-Vis range ( 280 to $800 \mathrm{~nm}$ ). In the visible range (350-700 nm), synthetic dyes absorb radiation in proportion to the concentration according to the Lambert-Beer law (Brode et al. 1952; Bhattacharyya and Sarma 2003; Hamada et al. 1985; Tunç et al. 2012; Saeed et al. 2009; Scarminio and Kubista 1993). Study of the effectiveness of removing of a single dye from a solution involves comparing the absorbance at the maximum absorption for a particular dye. In the case of mixtures of different dyes, like in the real wastewater, efficiency of the process can be determined by comparing the area under the absorption curves before and after the cleaning process and after the processes following treatment, for example, centrifugation of sedimentation.

Testing the composition of wastewater from dyeing industry is important to check the effectiveness of treatment methods. The research on the COD, chloride content, $\mathrm{pH}$ value, suspended solids content, dry residue and amount of dissolved substances and color and suspension reduction degree in the wastewater from dyeing plants was described in a separate article (Names of the authors 2016). The aim of this study was to determine the effectiveness of treatment processes of colored wastewater coming from the textile industry, taking into account not only quantitative but also qualitative differentiation. The composition of wastewater determines the need for specific procedures of the physicochemical and biological treatment, as the commonly used synthetic dyes are decomposed according to unequal mechanisms and under different conditions. The use of universal purification procedures does not always lead to expected results from the point of view of the quality parameters of treated water (Kyzioł-Komosińska et al. 2009; MajewskaNowak 1986).

Samples of colored wastewater were collected in 2016 from five dyeing plants of various sizes and of different

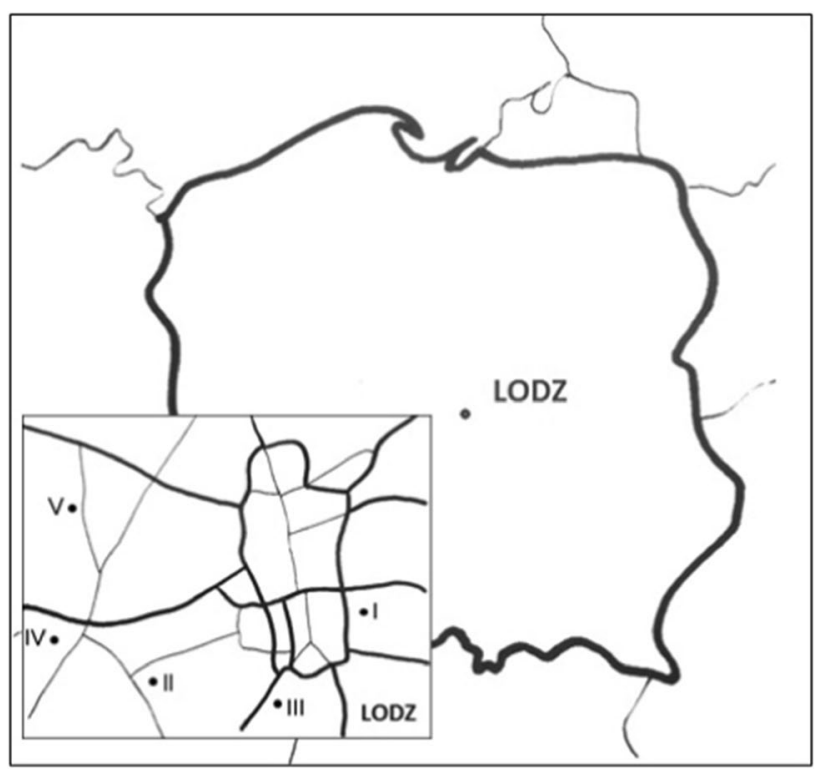

Fig. 1 Location of the studied dyeing plants in the Lodz region

types of dyed fabrics and dyes used. The locations of the plants are shown in Fig. 1.

\section{Materials and methods}

\section{Wastewater samples}

The test samples were collected from 5 dyeing plants located in the Lodz region, Poland (Fig. 1). Two samples were taken from each dyeing plant-a raw wastewater sample (before treatment) and the other one after the treatment in the on-site treatment plant. Before the analysis, the wastewater samples were stored in $1 \mathrm{dm}^{3}$ polypropylene bottles at $4{ }^{\circ} \mathrm{C}$ and measured within two days. The samples were sedimented for half an hour and centrifuged (2500 RPM, $10 \mathrm{~min}$.) or not (to assess the effect of centrifugation, see Results and discussion) before spectrophotometric analysis.

\section{Spectrophotometric analysis}

For tested wastewater samples, spectra of raw sewage $(R)$ from five dyeing plants $\mathrm{I}-\mathrm{V}$ were recorded on the device Hitachi U-2800, using a dedicated program UV HITACHI SOLUTIONS, analyzing of absorption changes in the wavelength range $280-800 \mathrm{~nm}$ at $\Delta \lambda=2 \mathrm{~nm}$. Then, the same analysis was performed for samples after the treatment process $(T)$ and also for samples after centrifugation of raw (RC) and 
treated sewage (TC). The area under the plot was calculated for each spectrum to determine the degree of color reduction after purification. Results were presented as residual color (percent of the color of the raw sample).

\section{Numerical analysis}

For the purposes of the analysis, the scope of investigation was narrowed down to the visible range of 350-750 $\mathrm{nm}$. The spectrum of the analyzed wastewater after treatment was subjected to normalization with respect to the spectrum of raw sewage for $\lambda_{\max }$ in the range of $350-750 \mathrm{~nm}$.

Normalization was carried out for $\lambda_{\max }$ of raw sewage ( $R$, absorbance $A_{\mathrm{R}}$ ) and tested wastewater (X) in accordance with the relation $\alpha=A_{\mathrm{R}} / A_{\mathrm{X}}$ where $A_{\mathrm{X}}$ is the absorption of centrifuged wastewater (RC), treated wastewater $(T)$ or treated and centrifuged wastewater (TC). Normalization was done so that the absorbance values at $\lambda_{\max }$ for both spectra were equal $\left(\Delta A_{\lambda \max }=0\right)$. Then, the differential spectrum was obtained by subtracting the analyzed spectra from each other (Fig. 2).

The efficiency of the purification process was assessed by comparing the areas (S) under the curve in the ranges of 350-750 nm, by the formula: for raw sewage $\left(S_{\mathrm{R}}\right)$, raw and further centrifuged $\left(S_{\mathrm{RC}}\right)$, treated $\left(S_{\mathrm{T}}\right)$ and purified and further centrifuged $\left(S_{\mathrm{TC}}\right): S_{1}=S_{\mathrm{R}}-S_{\mathrm{RC}}, S_{2}=S_{\mathrm{R}}-S_{\mathrm{T}}$, $S_{3}=S_{\mathrm{R}}-S_{\mathrm{TC}}$ (see sections "Dyeing Plant I-V").

The differences in the areas of the normalized spectra of treated and centrifuged wastewater were calculated according to the formula (for $\Delta A_{\lambda \max }=0$ ): $\sum_{350}^{750}\left(\left|\int_{\beta 50}^{\lambda 1} \Delta S d \lambda\right|+\left|\int_{\lambda 1}^{\lambda 2} \Delta S d \lambda\right|+\left|\int_{\lambda 2}^{\lambda n} \Delta S d \lambda\right|+\ldots\left|\int_{\lambda n}^{750} \Delta S d \lambda\right|\right)=\Delta S$,

where $\lambda_{1}, \lambda_{2} \ldots \lambda_{\mathrm{n}}$ are the wavelength for spectra after normalization for $\Delta A_{\lambda \max }=0$.

The shape of the spectra indicates the nature of impurities remaining after the purification process and the area under the differential curve is proportional to their quantity. The locations of the minima of the component spectra (for a single impurity) were calculated from the second derivative of the function $A=f(\lambda)$.

Method of quantitative analysis of multicomponent mixtures, without knowledge of the component spectra, is based on a separation of the overlapping bands in the tested spectrum. This derivative method is used for accurate analysis of spectra of mixtures by spectroscopic methods UV-Vis, IR, Raman. The derivatives are obtained by calculation from the individual experimental data points. For the second derivative, the values of $d " A / d \lambda$ " are zero at the inflection points of the absorption spectra according to the rule of differentiation at the position of $\lambda_{\max }$. A minimum value is obtained, which in turn makes it possible to locate the absorption maximum very precisely. It allows to assess the number of individual absorption bands, which are assigned to individual components of the mixture, and the location of their $\lambda_{\max }$ in the spectrum of the examined solution. Analysis of the second derivative is a good method of analysis, independent of the scale on which spectra are recorded. It is recommended as a standard procedure for the spectra recorded as a wavelength-dependent linear function (Antonov and Stoyanov 1995; Antonov and Nadeltcheva 1996, 2000; Antonov 1997; Antonov and Petrov 2002; Wojciechowski et al. 2014).
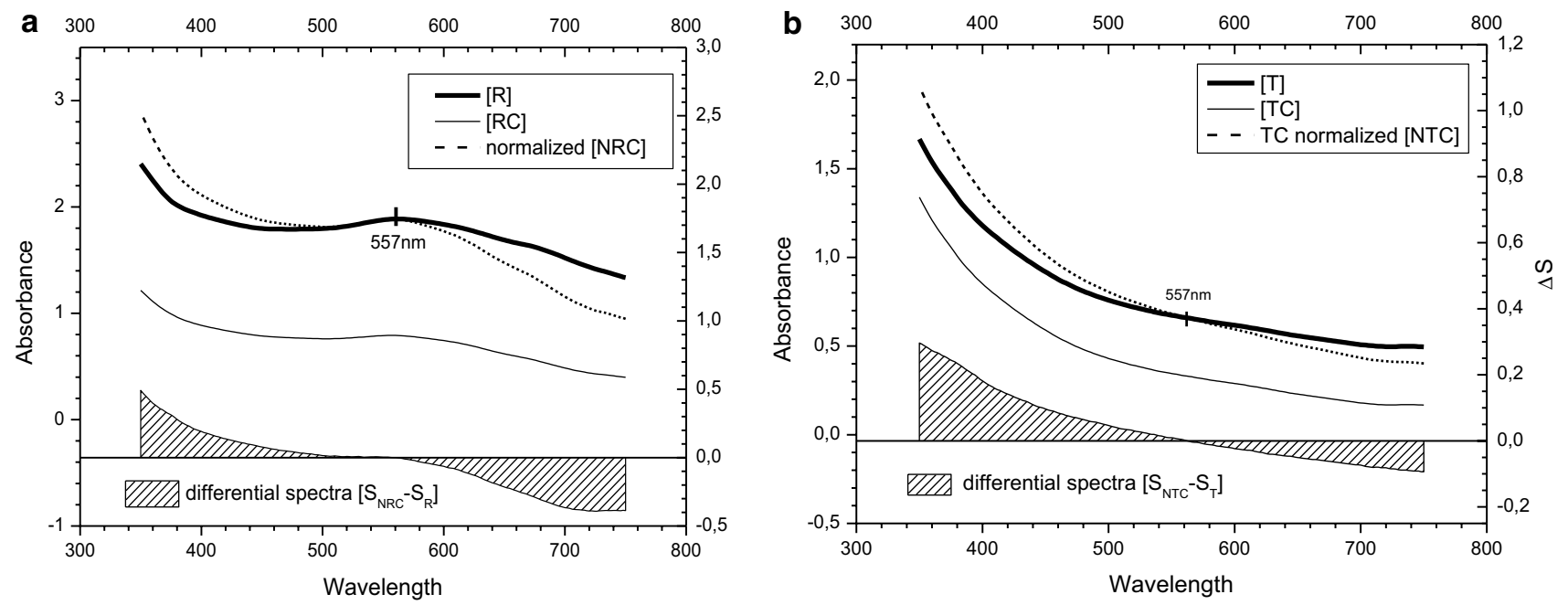

Fig. 2 Differential spectrum of a raw wastewater $(R)$ and centrifuged raw wastewater (RC) and the spectrum of $\mathbf{b}$ treated wastewater $(T)$, centrifuged treated wastewater (TR), the spectrum normalized (NRC, NTC) and differential $\left(S_{\mathrm{NRC}}-S_{\mathrm{R}}, S_{\mathrm{NTC}}-S_{\mathrm{T}}\right)$ 
In order to improve the signal-to-noise ratio of the absorption bands, the second-order Savitzky-Golay numerical method for 5 measuring points was used. This method can reduce measurement noise without reducing the quality of information. Simplicity is a consequence of the good signalto-noise ratio in the original spectra curves. In the curve of the second derivative, a good resolution can be obtained with regard to clearly detectable negative peaks that can be used for estimation of the number of overlapping bands as well as their positions. This procedure results in a smoothed spectrum (Savitzky and Golay 1964; Steinier et al. 1972).

Calculations were performed using the program Origin Pro v.8.6.0 (OriginLab Corp.).

\section{Results and discussion}

Dyes from different manufacturers and belonging to different groups were used in the dyeing plants tested. They absorb light from the entire range of UV-Vis, from the green-andyellow (approx. $380 \mathrm{~nm}$ ) to blue and violet $(620-700 \mathrm{~nm}$ ) and contain typical chromophore systems in their chemical structure, known for many years. Modifications of their structure change their application and functional properties (Colour Index International 1999). Spectrophotometric analysis indicates that the tested dyeing plants most often dye fabrics in shades of purple and blue. First, the location of the absorption maxima of the tested sewage samples in the range of 350-750 nm was determined (Table 1). This range includes the visible range of absorption, in which usable dye forms absorb (exception-optical brighteners).

The standard method of analysis covers the range of 200-800 $\mathrm{nm}$, that includes ranges invisible to the human: 200-380 $\mathrm{nm}$ and $700-800 \mathrm{~nm}$. Security requirements dictate the need to remove any colored impurities from wastewater, since they affect not only the aesthetics of waterways, but also impede the process of photosynthesis of aquatic plants acting as natural dissolved filters. Products of their decomposition, generally colorless, may also be harmful. They may have mutagenic and carcinogenic properties, especially when they were formed in the reactions of compounds belonging to the A1class of hazard of MAK III (substances definitely known to be cancerogenic in humans) or come from unknown manufacturers or importers (Christie and Standrino 1990; MAK Value List 1994).

The numerical analysis of the absorption bands used in this work allows to identify in detail the composition of the wastewater and the share of each of the individual dyes, mainly from the point of view of color. It also allows to assign them to the appropriate group (acid dyes, direct, reactive, etc.). Identification of dyes and their usable class also allows to select a suitable and effective method of their disposal.

For the selected value $\lambda_{\max }$, spectra of samples of the tested solutions were normalized so that the absorbance values (A) at $\lambda_{\max }$ are equal (Fig. 1). Then, the corresponding values of the function $A=f(\lambda)$ were subtracted from each other in the whole range of the analyzed spectrum.

The applied procedure of spectra normalization allows to determine the impact of all processes: centrifugation, physicochemical and biological methods on the effectiveness of wastewater treatment. Colored wastewater treatment can be analyzed for selected process independently or as a result of all employed operations. This is important given that the dyes or their mixtures do not decompose in the standard, uniform biological procedures and every time they require appropriate modifications of treatment methods. Synthetic dyes, in definition, must be durable in the process of use, therefore in the natural environment they do not have natural antagonists and their aerobic degradation is slow. Anaerobic processes are more effective, but they are difficult to apply in wastewater treatment practice.

First, calculations of efficiency of the wastewater treatment process in the range of $200-800 \mathrm{~nm}$ were made and then they were correlated with the results for a selected range of visible light of 350-750 nm. This calculation method did not analyze the specific absorption and the change in absorbance $(A)$ of various forms of dyes, analysis concerned changes in the whole spectral range. The calculation results are presented in Table 1.

Then, the analysis of the second derivative of the absorption bands was performed. This analysis aims to identify the
Table 1 The degree of purification (as a residual color, in \%) of colored wastewater in dyeing plants $I-V$ calculated by spectrophotometric analysis

\begin{tabular}{|c|c|c|c|c|c|c|c|}
\hline \multirow[t]{2}{*}{ Plant } & \multicolumn{3}{|c|}{ Range $280-800 \mathrm{~nm}$} & \multirow[t]{2}{*}{$\lambda_{\max }(\mathrm{nm})$} & \multicolumn{3}{|c|}{ Range $350-750 \mathrm{~nm}$} \\
\hline & 2 & 3 & 4 & & 2 & 3 & 4 \\
\hline I & 47.23 & 54.46 & 34.62 & 557 & 41.99 & 35.41 & 17.76 \\
\hline II & 93.68 & 58.91 & 52.98 & 490 & 95.97 & 56.61 & 52.47 \\
\hline III & 75.33 & 81.49 & 60.25 & 584 & 74.85 & 52.36 & 34.77 \\
\hline IV & 77.25 & 30.30 & 26.83 & 570 & 76.76 & 21.85 & 19.25 \\
\hline V & 83.63 & 83.89 & 74.41 & 574 & 82.59 & 87.71 & 75.57 \\
\hline
\end{tabular}

$\lambda_{\max }$ - wavelength of max. absorption in range $350-750 \mathrm{~nm}, 2$-raw wastewater centrifuged (RC), 3 treated wastewater $(T), 4$-treated wastewater centrifuged (TC) 
Table 2 Location of the absorption maxima of raw or treated wastewater calculated by second derivative of absorption bands (e.g., Fig. 3b)

\begin{tabular}{|c|c|c|c|c|c|c|c|}
\hline \multirow{2}{*}{$\begin{array}{l}\text { Plant } \\
\text { I }\end{array}$} & \multirow[b]{2}{*}{$R$} & \multicolumn{6}{|c|}{ Absorption maxima $\lambda(\mathrm{nm})$} \\
\hline & & 422 & 482 & 559 & 615 & 678 & \\
\hline & $T$ & 378 & 436 & 562 & 610 & 675 & \\
\hline \multirow[t]{2}{*}{ II } & $R$ & 406 & 528 & 651 & & & \\
\hline & $T$ & 390 & 483 & 522 & 627 & & \\
\hline \multirow[t]{2}{*}{ III } & $R$ & 391 & 430 & 482 & 522 & 621 & \\
\hline & $T$ & 516 & 563 & 640 & & & \\
\hline \multirow[t]{2}{*}{ IV } & $R$ & 437 & 478 & 524 & 621 & & \\
\hline & $T$ & 377 & 423 & 469 & 516 & 560 & 602 \\
\hline \multirow[t]{2}{*}{ V } & $R$ & 378 & 452 & 568 & 614 & & \\
\hline & $T$ & 379 & 460 & 570 & 615 & & \\
\hline
\end{tabular}

$R$-row wastewater, $T$ - treated wastewater dyes used and their colors. It allows to estimate the amounts of the colored components or various forms of dyes by calculating the second derivative of the absorption bands and to specify the location of hidden absorption bands (minima of the function $\mathrm{d} " A / \mathrm{d} \lambda \lambda^{\prime}$ ) which determine the color of the components of colored wastewater (Table 2).

In this work, the effectiveness of color wastewater treatment processes by physicochemical and biological methods with additional centrifugation after the treatment was examined. For this purpose, the spectrophotometric analysis of raw wastewater in the visible range $350-750 \mathrm{~nm}$ before and after purification was made. In addition, by analyzing the IIderivatives, the qualitative composition of treated wastewater was determined (by designating the absorption maxima). The results are shown in Table 2; an exemplary method of analysis is shown in Fig. 2.

\section{Analysis of the composition of colored wastewater from selected plants}

\section{Dyeing Plant I}

The dyeing processes in Plant I apply dyes belonging to the groups: reactive for wool and cotton, acid, disperse and cationic for synthetic fibers of brands such as Synezol, Bezactive, Remazol, Procion, Dianix, Serilen, Isonyl, Econyl, Gryfalan, Lanasol, Astrazon and Yoracryl. The dyeing process also uses accompanying substances as salt, acetic acid, hydrogen peroxide, hydrosulfite, ammonium sulfate, ammonia and caustic soda. Fabrics are dyed most often in shades blue and purple.

The dyeing plant has its own on-site treatment plant using flow tanks where the temperature parameter is averaged by heat recovery and the $\mathrm{pH}$ parameter-using hydrochloric acid.

The process of centrifugation of raw sewage does not change the qualitative composition of color impurities. The changes are related to their concentrations, probably due to adsorption on the particles surface. Second-derivative absorption bands $A=f(\lambda)$ for not centrifuged and centrifuged wastewater are of similar shape and have very similar values $\lambda$ of hidden absorption bands (Fig. 3b). A significant difference $\Delta S$ of raw and centrifuged sewage indicates significant contamination by the suspensions, also colorful. Mechanical cleaning (in settling tank) followed by centrifugation can remove more than $80 \%$ of pollutants (Table 1). Only centrifugation of raw sewage removes these impurities by almost $58 \%$.

The mechanical cleaning reduces the concentrations of all colored impurities, especially dyes absorbing in the range up to $\lambda_{\max }=557 \mathrm{~nm}$. This dyeing plant is characterized by a very high discharge of colorful wastewater with significant content of suspensions (Table 3). The very process of centrifugation of raw wastewater can remove most of the insoluble impurities. Even after the purification process, a considerable amount of suspension remains in the wastewater, and centrifugation reduces the impurity content by a further $18 \%$ in relation to the non-centrifuged treated wastewater (Table 1).

This may be due to the presence of poorly water-soluble dyes (i.e., disperse dyes) from a palette of yellows and greens of $\lambda_{\max }<562 \mathrm{~nm}$. In the area $\lambda_{\max }>562 \mathrm{~nm}$, a small change in color is observed. Only the dye(s) absorbing at about 690-700 $\mathrm{nm}$ has been removed from the wastewater in a larger amount (Fig. 3b). The analysis of changes in d"A/ $\mathrm{d} \lambda "=f(\lambda)$ ) indicates a considerable share of red and blue dyes in the wastewater.

\section{Dyeing Plant II}

Dyes belonging to the following groups were used in the dyeing processes in Plant II: reactive, acid, direct and disperse dyes of brands such as Novacron, Solophenyl, Lanasol, Remazol, Serilen, Hollactive and Holcron. The dyeing processes also used accompanying substances, such as soaps, 

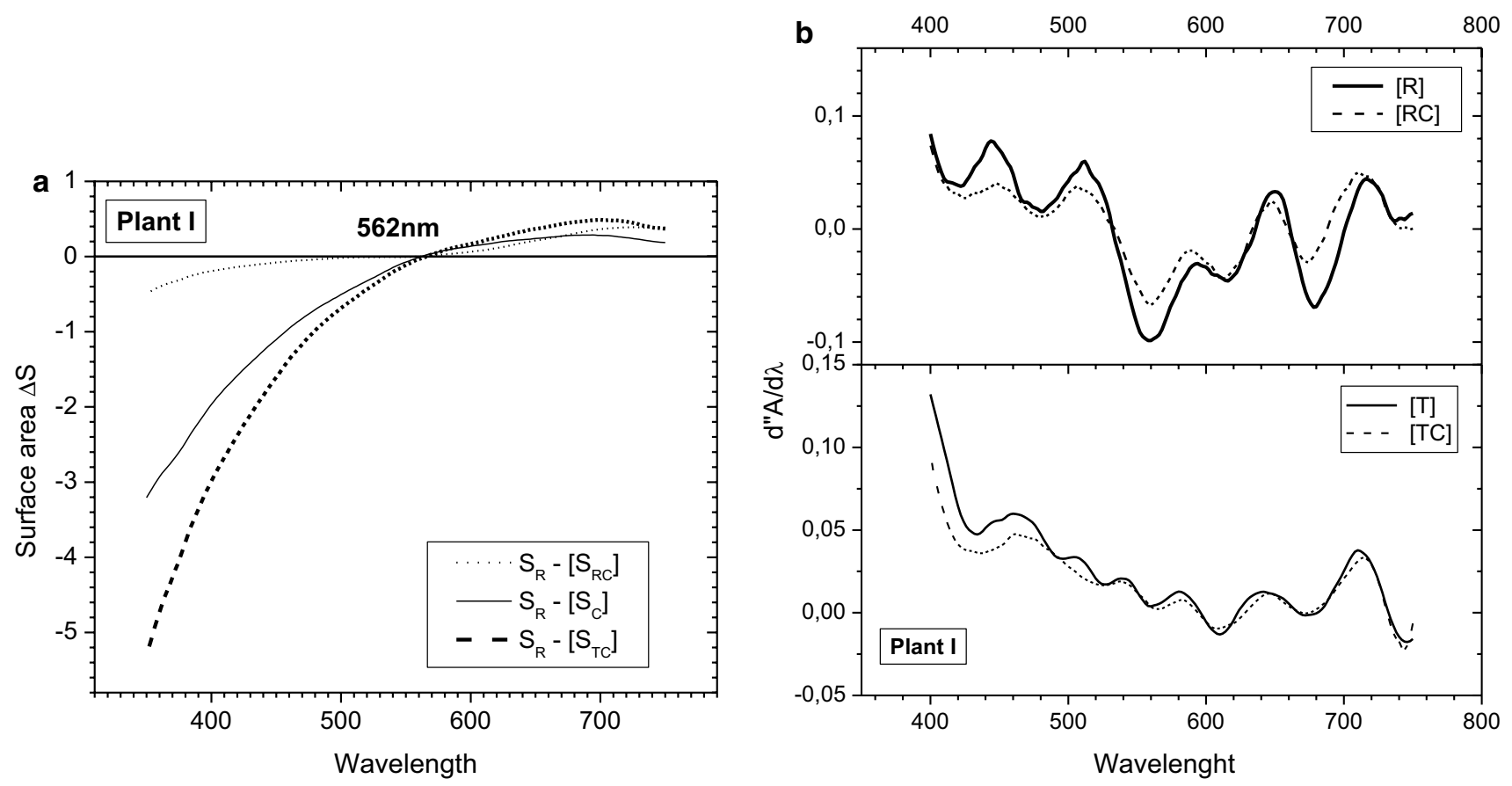

Fig. 3 a Differential spectra of raw $(R)$ and treated wastewater $(T)$, with $(C)$ and without centrifugation (TC) in the Plant I and b second-derivative absorption bands

Table 3 Changes in the share of color impurities in the wastewater after purification processes and centrifugation in Plant II (area under the differential curve)

\begin{tabular}{llll}
\hline Range (nm) & RC & $T$ & TC \\
& $S_{1}$ & $S_{2}$ & $S_{3}$ \\
\hline $350-562$ & -25.21 & -257.97 & -390.51 \\
$562-750$ & 41.41 & 38.19 & 60.66 \\
Sum & 66.62 & 296.16 & 451.17 \\
\hline
\end{tabular}

$S_{1}=S_{\mathrm{R}}-\left[S_{\mathrm{RC}}\right] ; S_{2}=S_{\mathrm{R}}-\left[S_{\mathrm{T}}\right] ; S_{3}=S_{\mathrm{R}}-\left[S_{\mathrm{TC}}\right]$

$S_{\mathrm{R}}, S_{\mathrm{RC}}, S_{\mathrm{T}}, S_{\mathrm{TC}}$ - the area under the absorption curve of raw wastewater, centrifuged raw wastewater, treated wastewater and centrifuged treated wastewater, respectively. The sum is calculated using absolute values

transporters, reducers, hydrogen peroxide, ammonia, caustic soda and softeners.

The dyeing plant has a mechanical sewage treatment plant that uses the processes of filtration, sedimentation, neutralization and heat energy recovery.

The dyes from the violet and blue-violet palette are used the most in the examined plant.

The centrifugation process removes approx. $4 \%$ of color from raw wastewater (Table 1). A large change in color intensity is observed after physicochemical treatment and it concerns dyes with $\lambda_{\max }<500 \mathrm{~nm}$ and $\lambda_{\max }>560 \mathrm{~nm}$, i.e., dyes of shades of red and purple. In terms of the chemical structure, they are sulfonic derivatives of $\alpha$ - and $\beta$-naphthols and aminonaphthols used as acid-coupling components. The smallest effectiveness of the treatment was found for dyes with shades of yellow-green and green $\left(\lambda_{\max } 500-560 \mathrm{~nm}\right)$ and among dyes belonging to the palette of blues (Fig. 4a).

Although the concentrations of dyes change, the qualitative composition of colored wastewater before and after the treatment is the same, as evidenced by the spectral characteristics (Fig. 4b). This indicates that most of the dyes are soluble dyes used for dyeing of natural fibers by bath methods. The lower efficiency of the physicochemical treatment combined with centrifugation (see Table 4-the sum of differential areas is proportional to the efficiency of the treatment) indicates an increase in the concentration of dye in the wastewater, so the effectiveness of these two processes is lower than that of the treatment itself. Disaggregation of dyes may be the cause (Wang 2000). This is not evident in the decrease in the total absorbance of the sample (Table 1) due to the content of hard settling suspensions. The normalization of the spectrum and the analysis of the differential spectra make it possible to compare the changes in colored impurities concentrations.

\section{Dyeing Plant III}

The dyeing processes in Plant III used dyes belonging to the groups: acidic and metal complex for wool, multifunctional reactive dyes for cotton and disperse dyes like Lanasyn, 

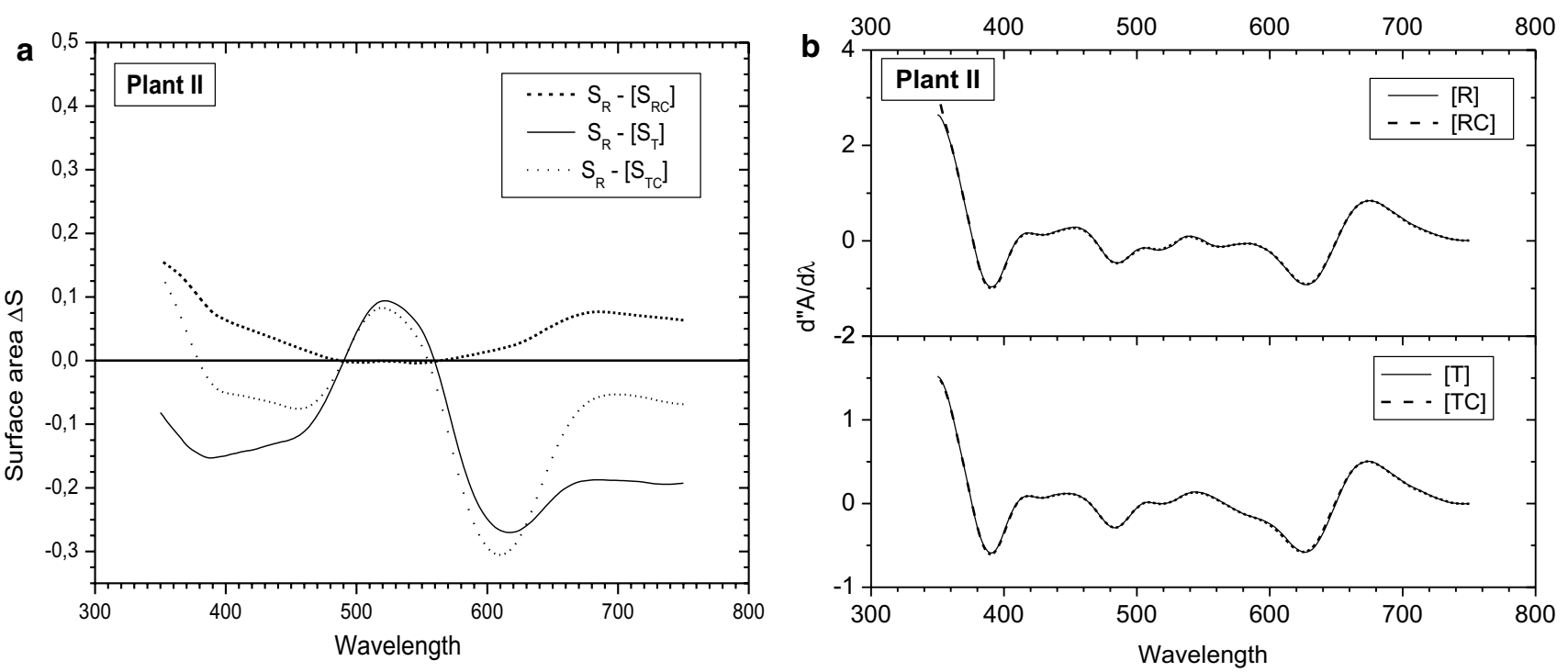

Fig. 4 a Differential spectra of $(R)$ and (RC) samples, treated with (TC) and without $(T)$ centrifugation in the Plant II and b second derivative of spectra absorption bands

Table 4 Changes in the share of color impurities in the wastewater after the purification processes and centrifugation in Plant I (area under the differential curve)

\begin{tabular}{llll}
\hline Range (nm) & RC & $T$ & TC \\
& $S_{1}$ & $S_{2}$ & $S_{3}$ \\
\hline $350-490$ & -8.11 & 16.56 & $* 1)$ \\
$490-560$ & 0.16 & -4.34 & -3.50 \\
$560-750$ & -8.76 & 37.71 & 27.29 \\
Sum & 17.03 & 58.61 & 38.77 \\
\hline
\end{tabular}

*1) $\left[S_{\mathrm{TC}}\right]$ in the range of $350-380 \mathrm{~nm} \Delta S=-2.08,380-490 \mathrm{~nm}$ $\Delta S=5.90$

Description of abbreviations is given in Table 3

Table 5 Changes in the share of color impurities in wastewater of the Plant III after the treatment processes and centrifugation (area under the differential curve)

\begin{tabular}{llll}
\hline Range (nm) & \multicolumn{1}{l}{ RC } & $T$ & TC \\
& \multicolumn{1}{l}{$S_{1}$} & $S_{2}$ & \multicolumn{1}{l}{$S_{3}$} \\
\hline $350-584$ & 8.23 & 153.74 & 204.29 \\
$584-750$ & -21.70 & $* 1)$ & $*_{2}$ \\
Sum & 29.93 & 172.83 & 214.36 \\
\hline
\end{tabular}

*1) $\left[S_{\mathrm{T}}\right]$ in the range: 584-642 nm $\Delta S=-4.54,642-750 \mathrm{~nm}$ $\Delta S=-14.55$

*2) $\left[\mathrm{S}_{\mathrm{TC}}\right]$ in the range: $584-678 \mathrm{~nm} \Delta S=-8.68,678-750 \mathrm{~nm}$ $\Delta S=-1.39$

Description of abbreviations is given in Table 3

Nysolan, Drimaren, Synezol, Kimsoline for polyester. The dominant color of dyeing is purple. In dyeing processes, the accompanying substances are also used such as dispersants, wetting agents, UV stabilizers, enzymes, adhesive and stiffening agents, hydrosulfite.

The plant uses an open horizontal flow sedimentation tank to treat colored wastewater.

Wastewater treatment at the Plant III allows to remove contaminants from wastewater with an average efficiency (Table 5). The largest share in the palette of dyes used is purples with $\lambda_{\max } \approx 560-620 \mathrm{~nm}$ and with good solubility. The centrifugation removes about $30 \%$ of impurities from raw wastewater and $20 \%$ from the wastewater treated by physical method. As in the case of sewage treatment at the Plant II, centrifugation of treated wastewater increases the concentration of the dyes with $\lambda>584 \mathrm{~nm}$, which could be the result of the disaggregation or desorption.

It can be observed in Fig. 4a, as in other cases described in this paper, that the centrifugation of raw sewage removes solid contaminants by approx. $25 \%$ (Table 5), while a significant change in the color of wastewater is not observed (Table 5 and Fig. 5b). Only physical and chemical treatment allows to remove most color impurities from the solution in shortwave range; centrifugation reinforces this effect (approx. 18\%), which indicates the presence of additional adsorbents in solution, derived from the decomposition of dyes or their aggregates.

Shades of purple and blue dominate among the dyes used with $\lambda_{\max }$ localized at about $620 \mathrm{~nm}$. The treatment efficiency of the investigated wastewater is high. It contains mostly soluble dyes and content of suspension does not exceed $6 \%$. Only the dyes absorbing in the range $570-620 \mathrm{~nm}$ cannot be easily removed by physical methods. As in Plant I, this is most likely due to the use of soluble dyes in the red palette, which are azo derivatives of 

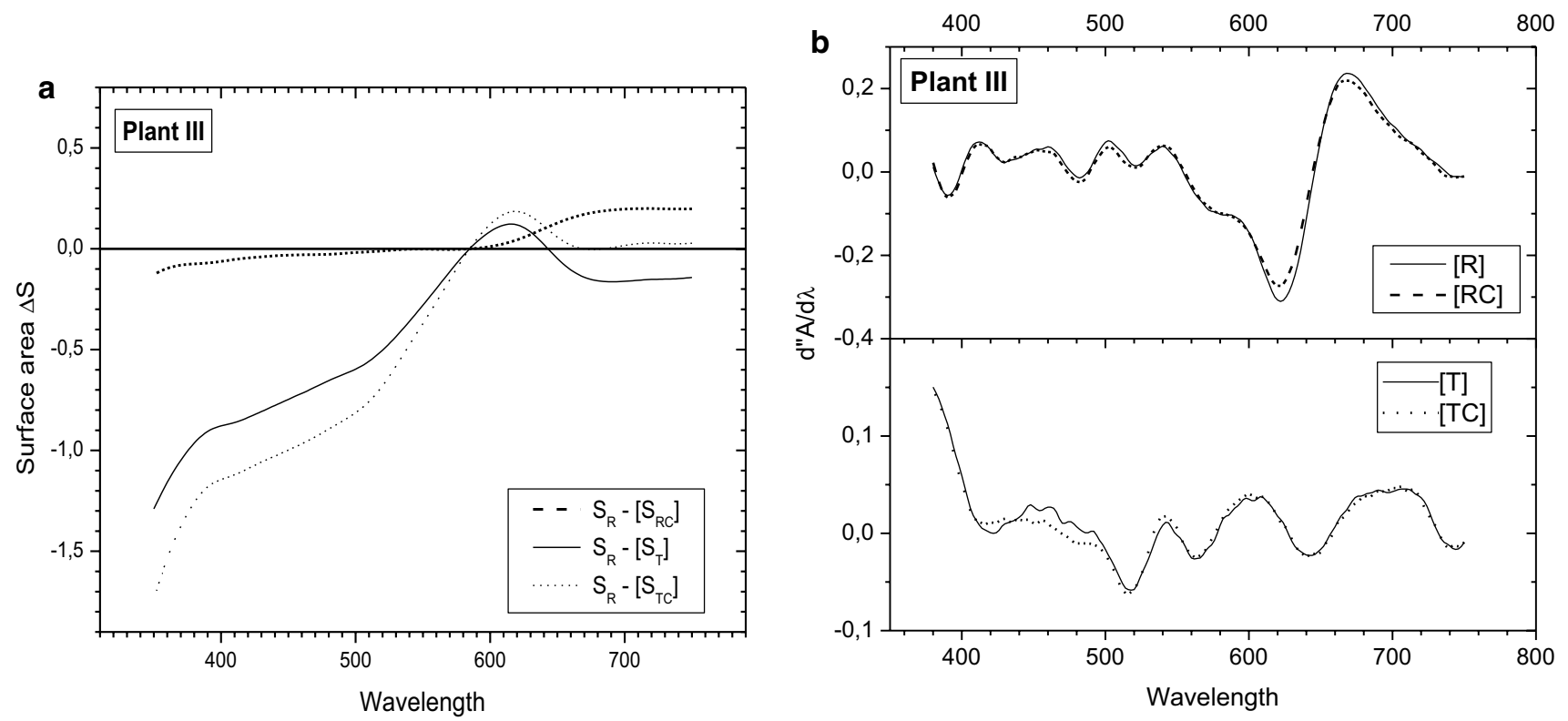

Fig. 5 a Differential spectra of raw $(R)$ and treated wastewater $(T)$, with and without centrifugation process in the Plant III and b second-derivative absorption bands

sulfonaphthols. Second-derivative analysis indicates that the dye with absorption maximum at the $\lambda_{\max }=584 \mathrm{~nm}$ consists of two forms with a batho-shifted absorption maximum. This dye is more resistant to treatment than the basic color contamination of wastewater (with $\lambda_{\max }=620 \mathrm{~nm}$ ). In the range of dyes that are discharged with the wastewater to the treatment plant, there are also o-hydroxyazo dyes. The form responsible for long wave absorption can be a hydrazone form that differs from the azo form, i.e., in use resistance. In analyzed case, it is less susceptible to physical and chemical processes. In this case, purification procedure different from the standard one should be applied, before possible re-use of treated wastewater.

\section{Dyeing Plant IV}

In the dyeing processes in the Plant IV, typical and additional finishing were used as bleaching, washing, refining and digital printing of knitted and woven fabrics. The types of applied dyes are not known. The plant is characterized by the most advanced technology among described, and the amount of wastewater discharged into the sewage system is over $75 \mathrm{~m}^{3} / \mathrm{h}$. The treatment plant consists of the following modules: wastewater expansion tank, a tubular heat exchanger, $\mathrm{pH}$ correction and coagulation, a three-stage reactor without an anaerobic chamber, ozonation and stabilization of excess sludge. As the only one, this plant has a biological module of wastewater treatment. The dominant color of dyeing is purple. In the treatment Plant IV, the composition of wastewater and their properties differ significantly from the others. Centrifugation of raw sewage removes about $23 \%$ of suspensions and dyes with $\lambda_{\max }$ above $570 \mathrm{~nm}$, namely blues and violets. Only the process of physicochemical and biological treatment leads to remove the residual dyes in the field below $570 \mathrm{~nm}$. The efficiency of purification decreases when the physicochemical and biological processes are followed by additional centrifugation (Table 6). This may be due to aggregation or adsorption on biological material. The resulting aggregates may disintegrate during centrifugation, leading to an increase in the concentration of remaining colored impurities in solution (as a result of desorption from the biological material).

Table 6 Changes in the share of color impurities in the effluent after the purification and centrifugation processes in Plant IV (area under the differential curve)

\begin{tabular}{llll}
\hline & RC & $T$ & TC \\
\hline Range (nm) & $S_{1}$ & $S_{2}$ & $S_{3}$ \\
$350-570$ & $* 1)$ & 25.25 & -19.79 \\
$570-750$ & 56.62 & $* 2)$ & $* 3)$ \\
Sum & 5.71 & 37.53 & 32.55 \\
\hline
\end{tabular}

*1) $\left[S_{\mathrm{RC}}\right]$ in the range: $350-394 \mathrm{~nm} \Delta S=0.12,394-570 \mathrm{~nm}$ $\Delta S=-1.19$

*2) $\left[S_{\mathrm{T}}\right]$ in the range: $570-628 \mathrm{~nm} \quad \Delta S=-0.83,628-750 \mathrm{~nm}$ $\Delta S=11.46$

*3) $\left[S_{\mathrm{TC}}\right]$ in the range: $570-628 \mathrm{~nm} \Delta S=-0.88,628-750 \mathrm{~nm}$ $\Delta S=11.88$

Description of abbreviations is given in Table 3 

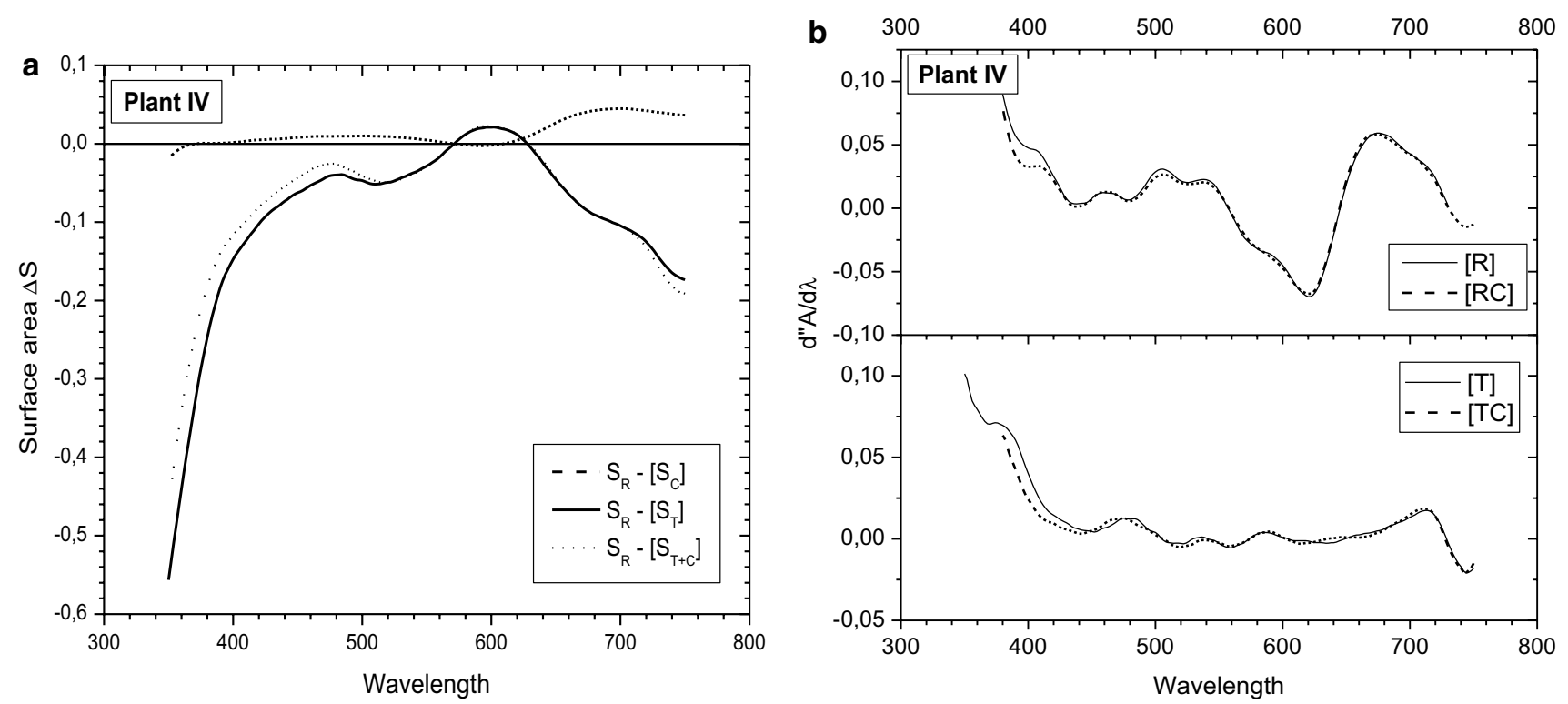

Fig. 6 a Differential spectra of raw $(R)$ and treated wastewater $(T)$, with and without centrifugation process in the Plant IV and $\mathbf{b}$ second-derivative absorption bands

Analysis of second derivatives of wastewater absorption curves before and after treatment indicates a significant change in the concentrations of color compounds in the solution (Fig. 6). For this plant, a high efficiency of wastewater treatment by physicochemical and biological methods is observed (Table 1). A clear decrease in the concentration relates to a compound with $\lambda_{\max }>628 \mathrm{~nm}$ (Table 6). Other colored impurities ranging below $628 \mathrm{~nm}$ are removed from the solution almost equally, resulting in a marked change of color on close to gray. The process parameters are therefore chosen optimally to the current conditions and the chemical composition of the colored wastewater.

Centrifugation of the biologically treated wastewater causes a slight increase in the concentration of the dyes at $\lambda<570 \mathrm{~nm}(3,5 \%)$ and the decrease for the dyes at $\lambda>620 \mathrm{~nm}$, i.e., from a palette of blues and purples.

\section{Dyeing Plant V}

The dye-work $\mathrm{V}$ is the smallest of the tested dyeing plants and dyes fibers like Lycra, microfiber, stretch and uses metal complex dyes and acid dyes: Lanasyn, Holegal. Accompanying substances are soap, fixing agents, $\mathrm{pH}$ adjusters. The dominant color of dyeing is purple, as in other investigated plants.

The wastewater from the dyeing process is pre-cleaned on sieves. During the second stage, it goes to the settling tank where the coagulation process with aluminum sulfate takes place. The wastewater after the dyeing process is stored in the Plant V in an overgrown, poorly maintained clarifier. Analysis of changes in the composition of the wastewater discharging into the sewage system indicates low effectiveness of treatment processes. The solids content of the raw sewage is approx. $17.5 \%$. After the purification process, approx. $12 \%$ can be removed additionally by centrifugation (Table 1). The composition of wastewater after purification in terms of color impurities is similar to that of raw sewage (Fig. 7b); the minor changes are observed only in the range of $\lambda$ up to $574 \mathrm{~nm}$ (Table 7), i.e., for dyes from a palette of yellow and green. Reds, blues and purples are practically not removed; their concentration (for dyes with $\lambda_{\max }<574 \mathrm{~nm}$ ) even increased (Fig. 7a, b).

The data in Table 1 show that in dyeing plant $\mathrm{V}$ both the raw sewage centrifugation and the physicochemical treatment process are ineffective. In addition, the second-derivative analysis shows that the composition of the wastewater and concentrations of colored impurities do not change during wastewater treatment and the raw sewage and treated sewage have a similar color. The maximum reduction in the absorbance value in this case (in the treated and subsequently centrifuged wastewater) is about $25 \%$.

\section{Conclusion}

The composition of colored wastewater from five selected dye-works that use synthetic dyes for dyeing natural and synthetic fibers in their production was examined. The range of colors used covered the entire spectrum of visible light, the dyes came from various manufacturers and importers. The analysis was performed using the spectrophotometric method, examining the wastewater before and after the 

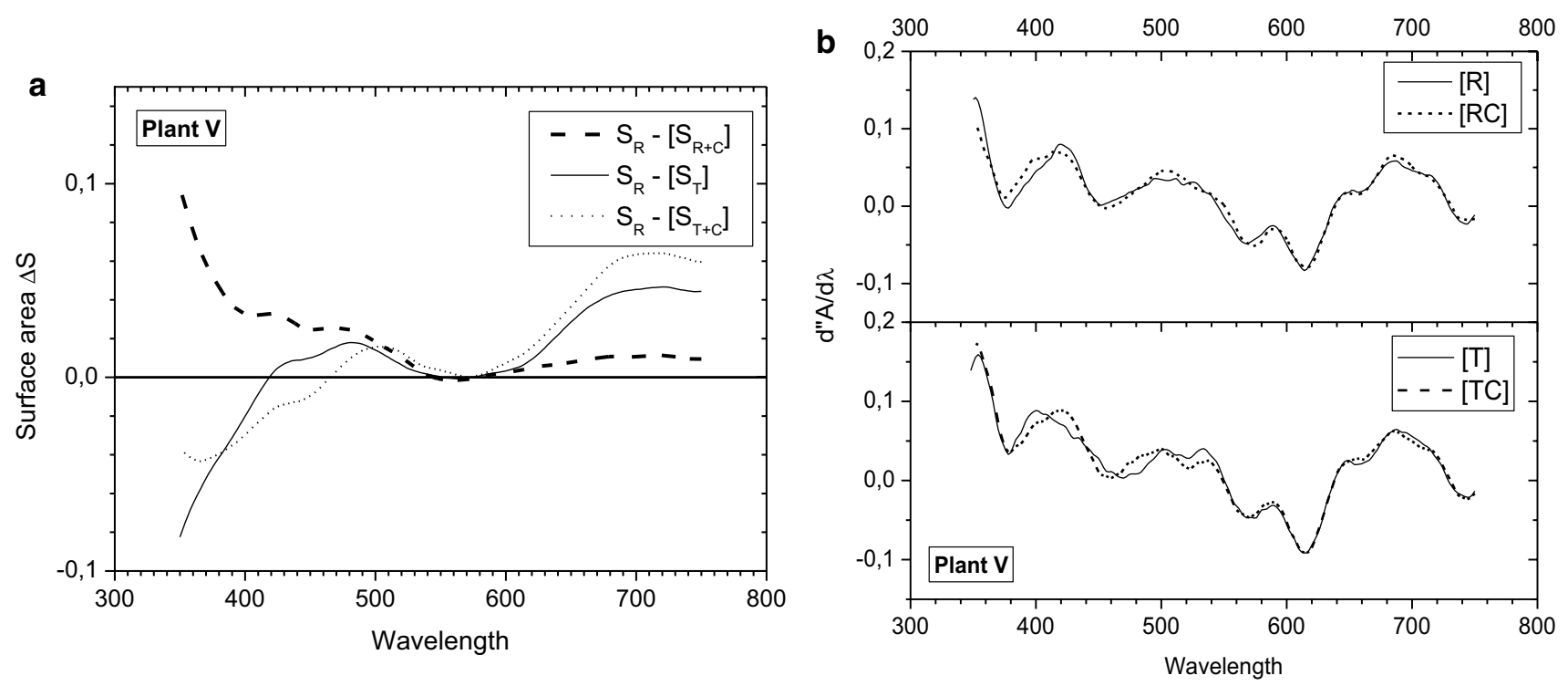

Fig. 7 a Differential spectra of raw $(R)$ and treated $(T)$ wastewater, with and without centrifugation process in the Plant V and $\mathbf{b}$ second-derivative absorption bands

Table 7 Change in the share of color impurities in the wastewater after the treatment process and the centrifugation in the dyeing plant $\mathrm{V}$ (area under the differential curve)

\begin{tabular}{llll}
\hline & RC & $T$ & TC \\
\hline Range (nm) & $S_{1}$ & $S_{2}$ & $S_{3}$ \\
$350-574$ & $* 1)$ & $* 2)$ & $* 3)$ \\
$574-750$ & -1.43 & -4.98 & -6.87 \\
Sum & 6.33 & 8.82 & 10.34 \\
\hline
\end{tabular}

*2) $\left[S_{\mathrm{RC}}\right]$ in the range: $350-530 \mathrm{~nm} \Delta S=-4.87,530-574 \mathrm{~nm}$ $\Delta S=0.03$

${ }^{* 2)}\left[S_{\mathrm{T}}\right]$ in the range: $350-418 \mathrm{~nm} \Delta S=2.59,418-574 \mathrm{~nm} \Delta S=1.26$

*3) $\left[S_{\mathrm{TC}}\right]$ in the range: $350-466 \mathrm{~nm} \Delta S=2.88,466-574 \mathrm{~nm}$ $\Delta S=-0.89$

Description of abbreviations is given in Table 3

treatment process using physicochemical and, in one case, biological methods. Using the second-derivative spectra, the basic components of colorful sewage and the position of their absorption maxima were identified. This allowed to determine the effectiveness of the methods used, also in relation to the group of dyes. This is important in the treatment process, as there are no universal methods for removing dyes from wastewater. They require different processes depending on their chemical structure which determines their color and application. The standard spectrophotometric method covers the range of $200-800 \mathrm{~nm}$. In this study, it was limited to the visible range $350-750 \mathrm{~nm}$, wherein an absorption of light by dyes used for dyeing natural and synthetic fibers is observed. The areas under the curves of absorption $A=f(\lambda)$ (Table 1), which is the general measure of the degree of contamination of wastewater, differ in these two ranges by $2-9 \%$ (except for the Plant III). The proposed analytical method allowed to identify the component of pollution and assign it to a specific color and the used class of dye. It was found that the centrifuging process, both before and after treatment, changes the composition of colored wastewater. The magnitude of these changes depends on the type of applied dyes, their belonging to the corresponding class (i.e., acid, direct, disperse dyes, etc.) or on the presence of dyes in the poorly soluble form under the specified conditions. Values described are specific for the sewage treatment plant and depend on the type of wastewater. In general, it can be noticed that dyes with reduced solubility in blue and green colors with $\lambda_{\max }$ above $550 \mathrm{~nm}$ are used in the dyeing plants tested.

Analysis of the second derivatives of the absorption bands of mixtures allows the identification of hidden absorption bands of individual dyes and their tautomeric forms. This relationship is characteristic for the particular discharge 
of pollutants. The composition of wastewater, however, is variable depending on the type and complexity of the process of dyeing. This analysis is based on the separation of bands overlapping in the analyzed spectrum and allows to evaluate the amount of absorption bands and the position of $\lambda_{\max }$ of components. This method can be used regardless of the spectrum registration range.

Acknowledgements The authors would like to thank the Editorial Submission Advisor of Springer Nature for his help in publishing the article.

Open Access This article is licensed under a Creative Commons Attribution 4.0 International License, which permits use, sharing, adaptation, distribution and reproduction in any medium or format, as long as you give appropriate credit to the original author(s) and the source, provide a link to the Creative Commons licence, and indicate if changes were made. The images or other third party material in this article are included in the article's Creative Commons licence, unless indicated otherwise in a credit line to the material. If material is not included in the article's Creative Commons licence and your intended use is not permitted by statutory regulation or exceeds the permitted use, you will need to obtain permission directly from the copyright holder. To view a copy of this licence, visit http://creativecommons.org/licenses/by/4.0/.

\section{References}

Antonov L (1997) Drawbacks of the present standards for processing absorption spectra recorded linearly as a function of wavelength. TrAC Trends Anal Chem 16(9):536-543. https://doi.org/10.1016/ S0165-9936(97)00064-2

Antonov L, Nadeltcheva D (1996) Resolution of overlapping bandsan idea for quantitative analysis of undefined mixture. Anal Lett 29(11):2055-2069. https://doi.org/10.1080/00032719608000811

Antonov L, Nadeltcheva D (2000) Resolution of overlapping UVVis absorption bands and quantitative analysis. Chem Soc Rev 29:217-227. https://doi.org/10.1039/A900007K

Antonov L, Petrov V (2002) Quantitative analysis of undefined mixture-cfishing net" algorithm. Anal Bioanal Chem 374:13121317. https://doi.org/10.1007/s00216-002-1600-8

Antonov L, Stoyanov S (1995) Resolution of overlapping UV-visible absorption bands: quantitative analysis of tautomeric equilibria. Anal Chim Acta 314:225-232. https://doi.org/10.1016/00032670(95)00281-4

Arora S, Saini HS, Singh K (2007) Decolorisation optimisation of monoazo disperse dye with Bacillus firmus. Identification of a degradation product. Color Technol 123:184-190. https://doi.org/ 10.1111/j.1478-4408.2007.00083.x
Banet IM, Nigam P, Singh D, Marchant R (1996) Microbial decolorization of textile-dye containing effluents: a review. Bioresour Technol 58:217-227. https://doi.org/10.1016/S0960-8524(96)00113-7

Beltran-Heredia J, Martin JS (2008) Azo dye removal by Moringa oleifera seed extract coagulation. Color Technol 124:310-317. https:// doi.org/10.1111/j.1478-4408.2008.00158.x

Bhattacharyya KG, Sarma A (2003) Adsorption characteristics of the dye, Brilliant Green on Neem leaf power. Dyes Pigm 57:211-222. https://doi.org/10.1016/S0143-7208(03)00009-3

Brode WR, Gould JH, Wyman GM (1952) The Relation between the absorption spectra and the chemical constitution of dyes. XXV. phototropism and cis-trans isomerism in aromatic azo compounds. J Am Chem Soc 74:4641-4646. https://doi.org/10.1021/ ja01138a059

Chang J-S, Kuo T-S (2000) Kinetics of bacterial decolorization of azo dye with Escherichia coli NO3. Bioresour Technol 75:107-111. https://doi.org/10.1016/S0960-8524(00)00049-3

Christie RM, Standrino PN (1990) Colour Chemistry, Peters AT, Freeman HS (ed) Elsevier Sci Publ Ltd, p. 255

Color Index International (1999) 3th ed., SDC Bradford

Dafale N, Rao NN, Meshram SU, Wate SR (2008) Decolorisation of azo dyes and simulated dye bath wastewater using acclimatized microbial consortium - biostimulation and halo tolerance. Bioresour Technol 99:2552-2558. https://doi.org/10.1016/j.biortech. 2007.04.044

Hamada K, Kubota H, Ichimura A, Lijima T, Amiya S (1985) Aggregation of an azo dyes in aqueous solution. Phys Chem 89:859-863. https://doi.org/10.1002/bbpc.19850890811

Hou A, Zhang X (2011) Decolorisation of reactive dye wastewater and the effect of surfactants using laccase. Color Technol 127:200 204. https://doi.org/10.1111/j.1478-4408.2011.00299.x

Houk J, Doa MJ, Dezube M, Rovinski JM (1991) Evaluation of dyes submitted under the toxic substances control act new chemicals programme. In: Peters AT, Freeman HS (eds) Colour chemistry. The design and synthesis of organic dyes and pigments Elsevier Sci Publ, London

Jędrzejczak M, Wojciechowski K (2016) Treatment efficiency of dyed wastewater. Chemik 70:150-157

Kalaf MA (2008) Biosorption of reactive dye from textile wastewater by non-viable biomass of Aspergillus niger and Spirogyra sp.. Bioresour Technol 99:6631-6634. https://doi.org/10.1016/j.biort ech.2007.12.010

Kumar K, Devi SS, Krishanamurthi K, Gampawar S, Mishra N, Pandya GH, Chakrabarti T (2006) Decolorisation, biodegradation and detoxification of benzidine based dye. Bioresour Technol 97:407-413. https://doi.org/10.1016/j.biortech.2005.03.031

Kyzioł-Komosińska J, Pająk M, Walor K (2009) The removal of dyes from textile wastewater using sorption method onto smectite clays. In: Ozonek J, Dudzińska M (eds) Polish environmental engineering. five years after joining the European Union 58:153-159. Monographs of the Committee of Environmental Engineering of the Polish Academy of Sciences (in Polish)

Li T, Guthrie JT (2010) Colour removal from aqueous solutions of metal-complex azo dyes using bacterial cells of Shewanella strain 
J18 143. Bioresour Technol 101:4291-4295. https://doi.org/10. 1016/j.biortech.2010.01.024

Maćkowska E, Gogolin R, Gaca J (2000) Dyeing wastewater treatment, III Polish Conference "Pro-ecological achievements in the chemical industry”, Torun (in Polish)

Majewska-Nowak K (1986) Dye removal from industrial wastewater. Environmental protection. PZITS, Wrocław

MAK (Maximale Arbeitsplatz-Konzentration) Value List 1994. Para III A1/A2

McKay RB (1963) The dye-staining of microorganisms: a review. Textile Res J 33:381. https://doi.org/10.1177/004051756303300509

Onat TA, Gumusdera H, Guvenc A, Donmez G, Mehmetoglu U (2010) Decolorization of textile azo dyes by ultrasonication and microbial removal. Desalination 255:154-158. https://doi.org/10.1016/j. desal.2009.12.030

Saeed R, Mughal MJ, Naeem M, Nuizami SS, Usmani TH (2009) Decolorisation of Remazol vinyl sulphone reactive dyes by potassium permanganate. Color Technol 125:277-283. https://doi.org/ 10.1111/j.1478-4408.2009.00207.x
Savitzky A, Golay MJE (1964) Smoothing and differentiation of data by simplified least square procedure. Anal Chem 36(8):16271639. https://doi.org/10.1021/ac60214a047

Scarminio I, Kubista M (1993) Analysis of correlated spectral date. Anal Chem 65:409-416. https://doi.org/10.1021/ac00052a017

Steinier J, Termonia Y, Deltour J (1972) Smoothing and differentiation of data by simplified least square procedure. Anal Chem 44:19061909. https://doi.org/10.1021/ac60319a045

Tunç S, Duman O, Kanci B (2012) Spectroscopic investigation of the interaction between cationic dye (C.I. Basic Yellow 2) and anionic surfactant (sodium dioctysulfosuccinate) in the premicellar and micellar region. Dyes Pigm 94:233-238. https://doi.org/10.1016/j. dyepig.2012.01.016

Wang JC (2000) A review of dye aggregation and its characterisation. Adv Colour Sci Technol 3:20-31

Wojciechowski K, Szuster L, Rutowicz J, Kamińska A (2014) Dyeing properties of CI Acid Blue193 and non-equivalent properties of CI Acid Black 194 produced by different manufacturers. Color Technol 130:215-220. https://doi.org/10.1111/cote.12084 